\title{
CÁLCULO DA POROSIDADE EM POÇOS DA BACIA DE ALMADA - BA COM BASE NUM CONJUNTO REDUZIDO DE PERFIS GEOFÍSICOS DE POÇO
}

\author{
SHIRLEY RABELO ${ }^{1} \&$ ABEL CARRASQUILLA ${ }^{2}$
}

\begin{abstract}
Resumo Em alguns poços de petróleo, os perfis geofísicos comumente empregados nas avaliações das formações geológicas correspondem ao conjunto dos perfis sônico, raios gama e resistividade, conhecido como Projeto DT (PDT). Na atualidade, os métodos modernos de estudo de reservatório implicam, preferencialmente, na análise desses perfis em conjunto com os perfis de densidade e de porosidade neutrônica, chamado de Projeto RHOB/NPHI (PRN). Empregando-se esses projetos, verificou-se a variação da porosidade efetiva $\left(\phi_{\mathrm{e}}\right)$ e da porosidade total $\left(\phi_{\mathrm{t}}\right)$, as quais se constituem em importantes parâmetros de um reservatório, na caracterização do volume de fluido na rocha. Nesse contexto, foram utilizados perfis de poço do Campo de Namorado na Bacia de Campos/RJ, que possui o conjunto completo de cinco perfis (PRN), no intuito de se avaliar a metodologia quando se emprega o PDT. Posteriormente, a técnica foi aplicada a dados da Formação Urucutuca na Bacia de Almada/BA, onde, pela disponibilidade deles, somente foi possível desenvolver o PDT. Os valores obtidos para $\phi_{e}$, nos reservatórios dos poços de Namorado, são da ordem de 0,25 a 0,30 para o PDT, e entre 0,30 e 0,35 para o PRN. Observa-se então que, o método utilizado no Campo de Namorado pode ser empregado na obtenção de $\phi_{\mathrm{e}}$ de reservatórios, fornecendo valores em média $15 \%$ menores do que os obtidos PRN. Para os perfis da Formação Urucutuca, o poço 1-BAS-36-BA os valores estimados de $\phi$, oscilaram entre 0,30 e 0,50 em média, apresentando um máximo de 0,65 ; e os de $\phi_{\mathrm{e}}$, variaram entre 0,30 e 0,35 em $57 \%$ dos dados. Para o poço 1-SSA-01-BA, entretanto, $\phi$ variou entre 0,30 e 0,65 com um valor máximo de 0,80; e $\phi$, variou entre 0,15 e 0,40 em $94 \%$ dos dados. Assim, conclui-se que é possível aplicar a abordagem proposta neste trabalho para estimar a porosidade de reservatórios de petróleo, em casos de exploração de bacias sedimentares, onde somente se possui um número limitado de perfis.
\end{abstract}

Palavras chaves: porosidade, perfis de poço, Bacia de Campos, Campo de Namorado, Bacia de Almada.

\begin{abstract}
POROSITY ESTIMATION IN GEOLOGICAL FORMATIONS OF ALMADA BASIN - BAHIA STATE - BRAZIL BASED IN AN INCOMPLETE SET OF GEOPHYSICAL WELL LOGS.. In some oil boreholes, the geophysical well logs commonly applied to evaluate the geological formations included a set of logs such as sonic, gamma ray and resistivity, known as Project DT (PDT). Nowadays, the modern methods of reservoir study involve analysis of those logs plus density and neutron porosity logs, called Project RHOB/NPHI (PRN). By using both projects, it was possible to calculate and verify the variation of the effective porosity $\left(\phi_{e}\right)$ and the total porosity $\left(\phi_{t}\right)$, which are important parameters to characterize the fluid volume in a rock. In this context, it was used well log data from Namorado Field located in the Campos Basin/RJ, which has the complete set of logs (PRN), and thus, it can be used to validate the methodology performed by PDT. Later, this methodology was applied to the available data from Urucutuca Formation in Almada Basin/BA, where only PDT it is possible to perform. The values obtained for $\phi_{\mathrm{e}}$ in the wells of Namorado Oil Field were around 0,20 to 0,30 for PDT, and, between 0,30 to 0,35 for PRN. In this case, it was observed that the applied methodology could be used to obtain $\phi_{\mathrm{e}}$ from reservoirs with values $15 \%$ smaller in average. On the other hand, in Urucutuca Formation logs the estimated values for $\phi$, for 1-BAS-36-BA well varied between 0,30 to 0,50 in average, reaching a maximum value up to 0,65 , and, $\phi_{\mathrm{e}}$ changed between 0,30 and 0,35 in $57 \%$ of the data. For $1-S S A-01-\mathrm{BA}$ well, $\phi_{\mathrm{t}}$ varied between 0,30 and 0,65 , reaching a maximum value of 0,80 , and $\phi_{e}$ differed between 0,15 to 0,40 in $94 \%$ of the data. Therefore, it is possible to conclude that the approach used in the present study can be applied to estimate the petroleum reservoirs porosity to the exploration of sedimentary basins, in situations where it is available only a limited number of logs.
\end{abstract}

Keywords: porosity, well logs, Campos Basin, Namorado Field, Almada Basin.

INTRODUÇÃO O estudo de caracterização de um reservatório compreende a análise de perfis geofísicos de poço, tais como o conjunto reduzido composto pelo perfil sônico ou tempo de trânsito (DT), resistividade (ILD) e raios gama (GR), denominado aqui de PDT. Por outro lado, a integração desses com os perfis de densidade (RHOB) e de porosidade neutrônica (NPHI), que corresponde à suíte básica de perfis atualmente empregada na indústria de petróleo, aqui denominada de PRN (compreendendo, portanto, os perfis DT, ILD, GR, RHOB e NPHI). Neste trabalho, essas duas metodologias de análise serão comparadas na geração dos valores de porosidade total $\left(\phi_{t}\right)$, dada pelo quociente do espaço vazio pelo espaço total da rocha, volume de argila $\left(\mathrm{V}_{\mathrm{sh}}\right)$, que é a quantidade percentual em volume de folhelho/ argila presente na rocha; e a porosidade efetiva $\left(\phi_{\mathrm{e}}\right)$, associada ao volume percentual da rocha disponível para ser ocupado pelo fluido. Esses parâmetros serão obtidos tanto por PDT como por PRN, através da utilização dos métodos de análise petrofísica do aplicativo PETROWORKS - PRO da empresa LANDMARK Graphics Corporation. Este aplicativo constitui uma ferramenta computacional de elevada aceitação e uso corrente na indústria petrolífera, para análise de dados de perfis geofísicos. Para realizar essa avaliação, foram utilizados dados geofísicos de cinco poços do Campo de Namorado, na Bacia de Campos/RJ. Uma vez confirmada a confiabilidade desta metodologia, no cálculo de $\phi_{\mathrm{t}}, \phi_{\mathrm{e}} \mathrm{e} \mathrm{V}_{\mathrm{sh}}$, a mesma foi aplicada a dois poços da Bacia de Almada (BA) atravessando a Formação Urucutuca, onde somente é possível aplicar o PDT. Esta formação exibe reservatórios turbidíticos, do tipo dos que integram complexos de canais, e semelhantes aos principais reservatórios de hidrocarbonetos das bacias brasileiras (Bruhn \& Moraes, 1989).

É bem conhecido que o perfil GR detecta a radioatividade total da formação geológica, sendo utilizado na identificação da litologia e no cálculo do volume de argilas ou argilosidade. O perfil NPHI, entretanto, faz uso do maior amortecimento dos

1 - Faculdade de Tecnologia Norte-Fluminense, Avenida Alberto Torres, 261, Centro, Campos dos Goytacazes - RJ, Fone: 022-2738-5503, http://www.facultec.com.br/ 2 - Laboratório de Engenharia e Exploração de Petróleo, Universidade Estadual do Norte Fluminense Darcy Ribeiro (LENEP/UENF), Rodovia Amaral Peixoto, Km 163, Av. Brennand, S/N, CEP: 29925-310, Imboacica, Macaé-RJ, Brasil. Fone: 022-2796-9700, http://www.lenep.uenf.br/ 
nêutrons rápidos pelas energias termais e epitermais do hidrogênio, do que aquele que acontece com elementos mais pesados na matriz da rocha. Desta forma, a resposta da ferramenta de nêutrons é função da quantidade de hidrogênio no material da rocha, e, como quase todo o hidrogênio nas formações geológicas ocorre devido à presença de água e/ou hidrocarbonetos nos poros das rochas, a resposta neutrônica é função direta da porosidade. Por outro lado, o perfil ILD fornece a leitura aproximada da resistividade da rocha $\left(\mathrm{R}_{t}\right)$, através da medição do campo magnéticos induzido nas rochas, a partir da qual e utilizando a Lei de Archie:

$$
R_{t}=\frac{a R_{w}}{\Phi^{m} S_{w}^{n}}, \text { (1) }
$$

calcula-se, indiretamente, a porosidade $\phi$. Nesta equação, $a$, $m, n, R_{w}$ e $S_{w}$ representam o coeficiente de tortuosidade, coeficiente de cimentação, coeficiente de saturação, resistividade da água de formação e saturação da água, respectivamente. $\mathrm{O}$ perfil DT, porém, mede a diferença nos tempos de trânsito de uma onda mecânica através das rochas, o que permite medir o grau de compactação das rochas, conhecer as constantes elásticas, detectar as fraturas e estimar a porosidade. Finalmente, o perfil RHOB detecta os GR defletidos pelos elétrons orbitais dos elementos componentes das rochas, após terem sido emitidos por uma fonte colimada situada dentro do poço, permitindo a determinação da densidade das formações, a identificação das zonas de gás e o cálculo da porosidade. Desta forma, na determinação da porosidade das rochas, cada técnica tem a sua respectiva capacidade de medir essa propriedade, e, em última instancia, são esses princípios físicos de funcionamento que, em boa parte, fornecem as diferenças verificadas nos valores ( $\mathrm{Hal}$ lenburg, 1997).

CONTEXTO GEOLÓGiCO As Bacias de Campos e Almada são bacias brasileiras que se estendem ao longo do litoral norte do Estado do Rio de Janeiro e na margem sul do Estado da Bahia, respectivamente. Ambas possuem uma evolução tectono - sedimentar muito semelhante às das outras bacias marginais do leste brasileiro, estando definidas por três seqüências estratigráficas distintas: continental, transicional e marinha, as quais representam os principais eventos geológicos formadores e modificadores destas bacias.

De acordo com o contexto geológico e estratégico da produção de petróleo, a Bacia de Campos pode ser dividida em três compartimentos: proximal, intermediário e distal. O compartimento proximal se localiza entre a linha da costa e a lâmina d'água de aproximadamente $100 \mathrm{~m}$. O intermediário, entre as cotas batimétricas de 100 e $2.000 \mathrm{~m}$, aproximadamente. E o distal, a profundidades de lâmina d'água maiores que $2.000 \mathrm{~m}$ até a região com muralhas de sal mais contínuas, que se localizam em torno de 3.000 m (SCHLUMBERGER, 1998). Nesta bacia existem dezenas de campos produtores de petróleo, dentre os quais o Campo de Namorado (Figura 1). Este campo foi o primeiro gigante da plataforma continental brasileira a ser descoberto, em novembro de 1975 pelo poço pioneiro 1-RJS-19. Encontra-se no compartimento intermediário da bacia, isto é, na porção central-norte do lineamento de acumulações petrolíferas, a $80 \mathrm{~km}$ da costa, em cotas batimétricas variando entre 110 e $250 \mathrm{~m}$, e apresenta como seu principal reservatório o Arenito Namorado, de origem turbidítica e idade Cenomiana inferior. Essa unidade sedimentar compõe a porção superior da Formação Macaé e, na área do campo, ocorre a profundidades variáveis entre 2900 e 3400 m (Meneses \& Adams, 1990).

Do mesmo modo, a Bacia de Almada (Figura 2) apresenta

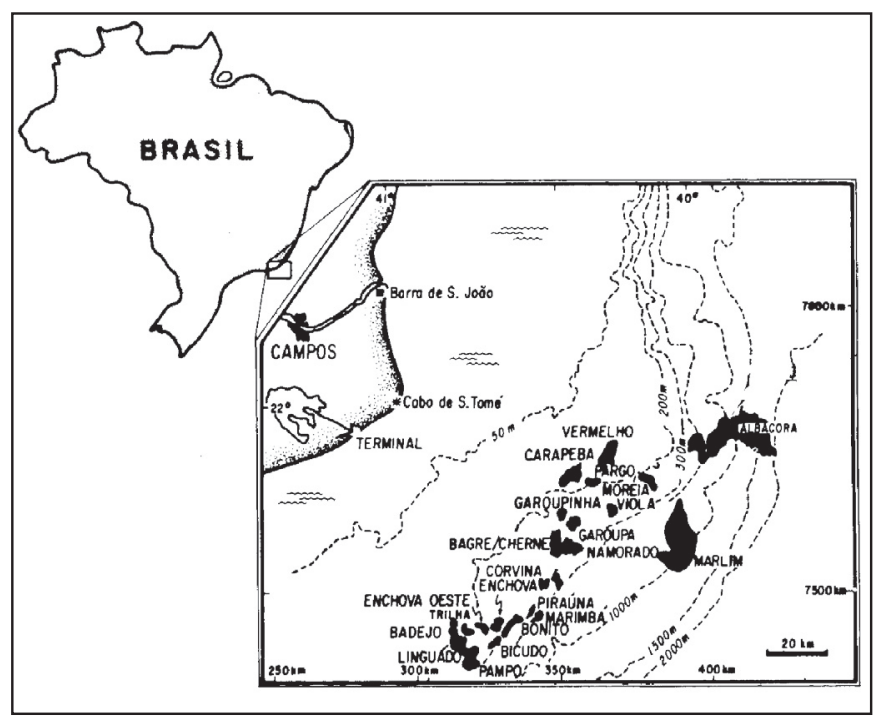

Figura 1. Localização da Bacia de Campos e do Campo de Namorado (modificado de Asmus \& Ponte, 1973).

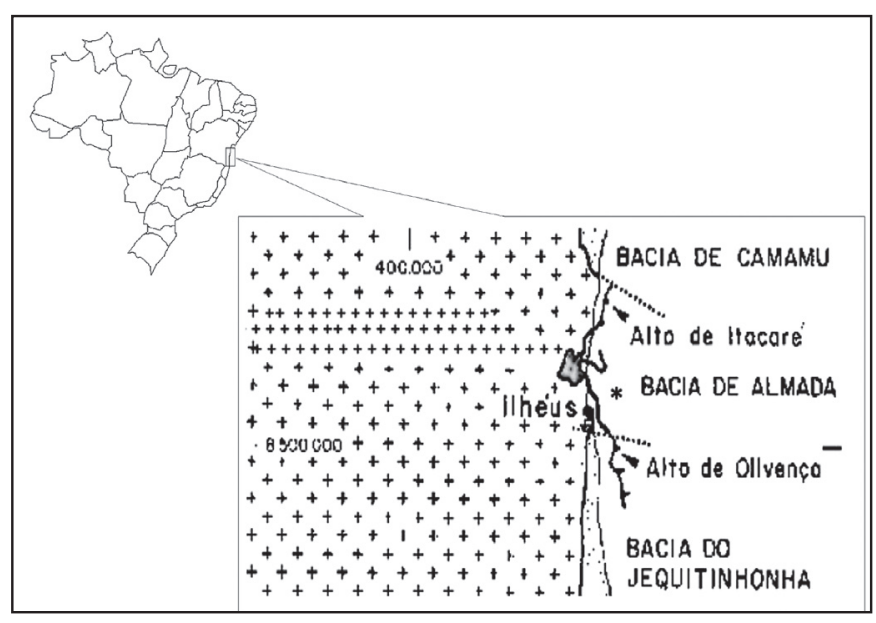

Figura 2. Localização da Bacia de Almada e do seu canyon submarino, este último apresenta-se preenchido por sedimentos da Formação Urucutuca (adaptado de Bruhn e Moraes, 1989).

uma evolução tectono-sedimentar definida por três seqüências estratigráficas distintas: continental ou rift, transicional e marinha. A porção emersa da bacia apresenta a seção aflorante da Formação Urucutuca, que é um sistema turbidítico canalizado, equivalente aos sistemas amplamente distribuídos nas bacias Meso-Cenozóicas brasileiras, como as Bacias de Sergipe-Alagoas, Espírito Santo e Campos. A Bacia de Almada apresenta, na sua seção exumada, um sistema petrolífero similar a outros que produzem petróleo em subsuperfície, constituindo-se, no dizer de Bruhn \& Moraes (1989), num excelente laboratório de campo para o estudo de reservatórios turbidíticos, os quais possuem grande importância econômica, pois, constituem os principais reservatórios de hidrocarbonetos no Brasil. No período de 1966 a 1985, foram perfurados, pela PETROBRAS, 14 poços exploratórios na Bacia de Almada, cinco na porção terrestre e nove na plataforma continental. Em 1977, foi perfurado um poço a $1 \mathrm{~km}$ da praia, na plataforma continental, com lâmina d'água de $11 \mathrm{~m}, 1$-BAS-36, cujos dados são utilizados neste trabalho. Esse poço atingiu o embasamento a $2.212 \mathrm{~m}$ e recuperou gás avaliado como subcomercial, com um volume de 

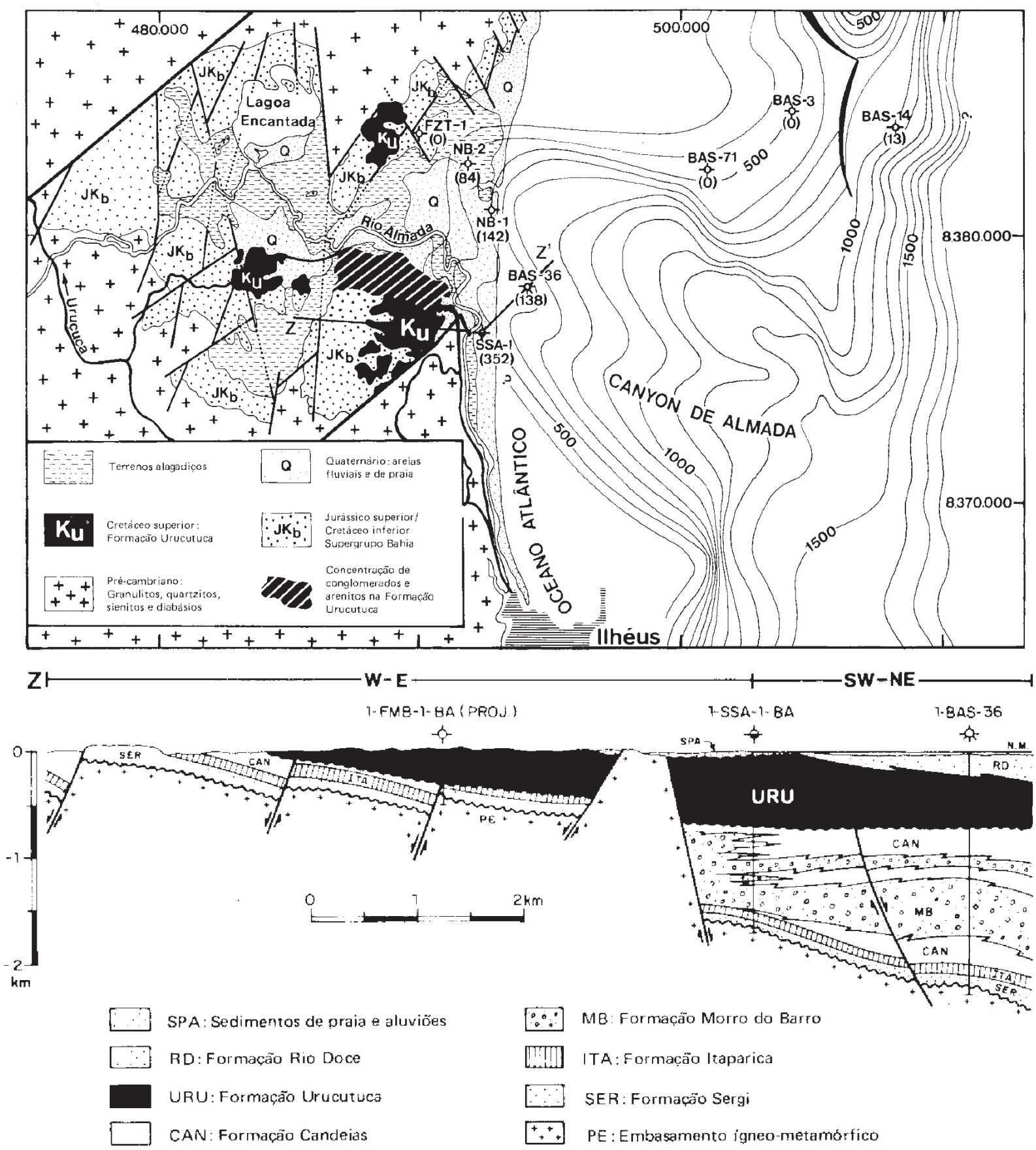

$\because:$ MB: Formação Morro do Barro
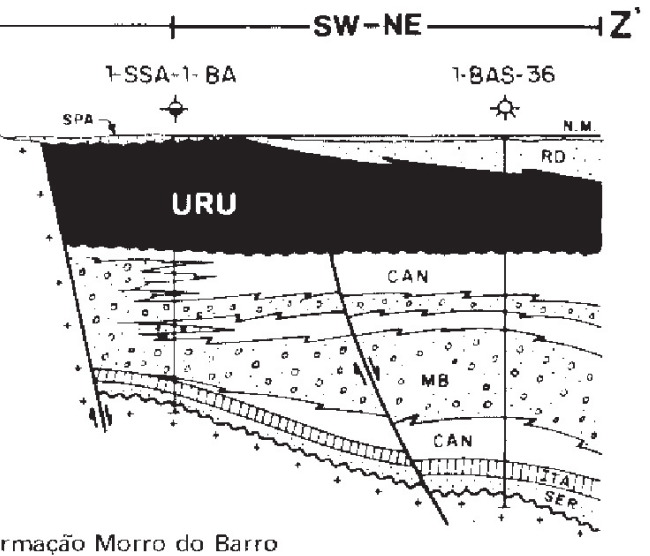

[T:T] ITA: Formação Itaparica

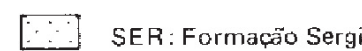

++ PE : Embasamențo igneo-metamórfico

Figura 3. Composição do mapa geológico da porção emersa da Bacia de Almada e a seção geológica no sul da bacia. Os dois poços analisados estão localizados na seção Z-Z' (adaptado de Bruhn e Moraes, 1989).

$34.000 \mathrm{~m}^{3} /$ dia (Milani et al., 2000). Em 1982 foi realizada uma campanha exploratória na área, com a perfuração de três poços pioneiros, dois dos quais estavam secos. $\mathrm{O}$ terceiro poço, o 1-SSA-1-BA, também estudado neste trabalho, recuperou óleo no Cretáceo Inferior (Formação Rio de Contas) e no Jurássico (Formação Sergi). Como se mostra na Figura 3, os poços acima mencionados atravessam a seção sedimentar até o embasamento cristalino passando pela Formação Urucutuca, a qual é constituída de reservatórios turbidíticos, que são o alvo do presente trabalho (Netto \& Sanches, 1991).

CONCEITOS TEÓRICOS Na obtenção dos valores de $\phi_{\mathrm{e}}$ para os Poços do Campo de Namorado e da Bacia de Almada, foi utilizado um fluxograma adaptado da metodologia do aplicativo PETROWORKS - PRO (Figura 4), para a obtenção de pa- râmetros petrofísicos a partir de dados de perfis. Esse programa foi projetado para determinar a porosidade, o volume de argila, a saturação de água, a permeabilidade e a litologia das rochas reservatório, fazendo parte do pacote OPENWORKS 2003, criado pela LANDMARK (LANDMARK, 2003).

Basicamente, existem dois tipos de aplicações nesse programa:

a) preparação de dados, onde se criam novas versões dos dados aplicando alguma correção ou transformação (etapas de criação do banco de dados, pré-correção ambiental, correção ambiental, pré-análise volumétrica e análise volumétrica); e,

b) interpretação de dados, onde se obtêm novos dados baseados em fórmulas empíricas para calcular $\phi_{\mathrm{t} \text { PDT }}, \phi_{\mathrm{e}}$ 


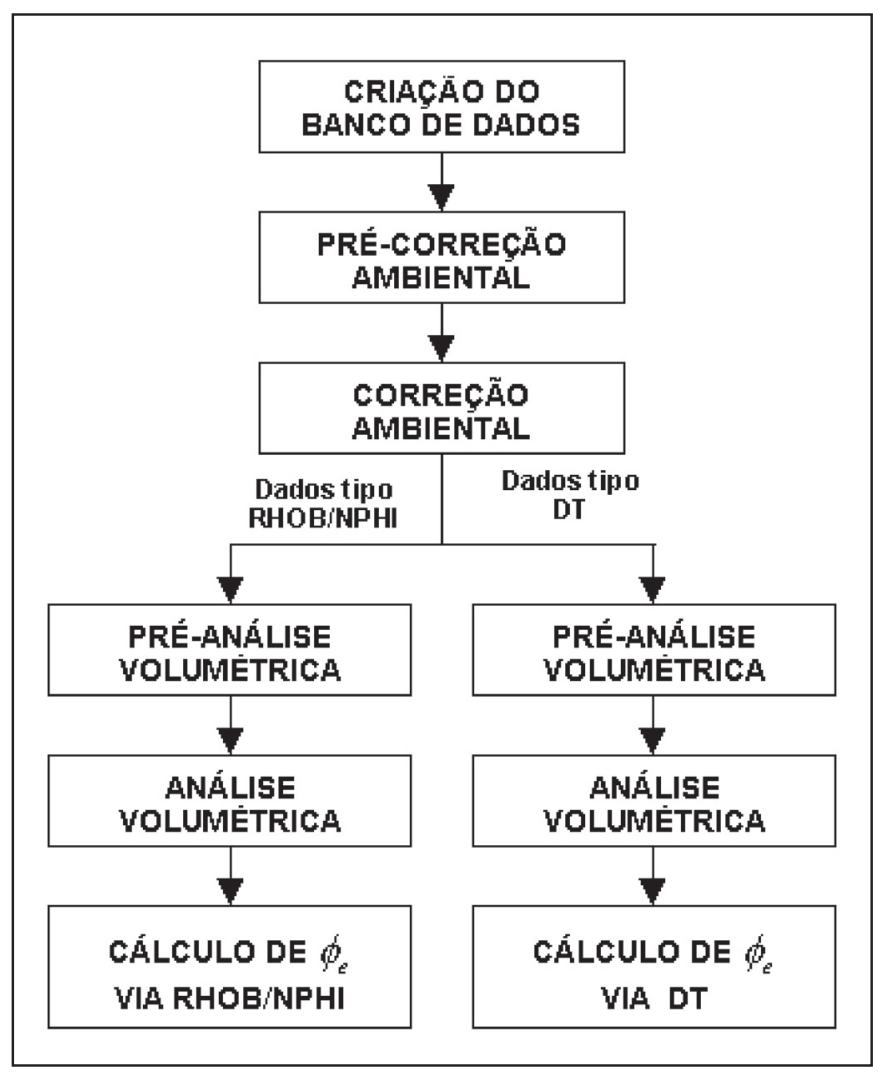

Figura 4. Fluxograma adaptado do aplicativo PETROWORKS - PRO para avaliação petrofísica.

$$
{ }_{\text {PDT }}, \phi_{\mathrm{t} \_ \text {PRN }} \text { e } \phi_{\mathrm{e} \_ \text {PRN }} \text {. }
$$

As etapas do fluxograma seguem a seqüência:

a) criação do banco de dados, que consiste no carregamento dos dados cadastrais de poço e das curvas de perfis;

b) pré-correção ambiental, que trata da criação e transformação de curvas, que serão utilizadas na correção ambiental, p. ex., criação da curva de temperatura através do cálculo do gradiente geotérmico e transformação fracionária da curva de NPHI;

c) correção ambiental, que corresponde à etapa de eliminação dos efeitos de poço dos perfis ILD, GR, RHOB e NPHI;

d) pré-análise volumétrica, a qual consiste no cálculo da $\phi_{\mathrm{t}}$ para ambos os conjuntos de perfis, conforme descrito a seguir:

1. Para a obtenção de $\phi_{\mathrm{t} \text { PDT }}$ foi usada a relação de Wyllie et al. (1956) com correção de fluido:

$$
\phi_{t_{-} P D T}=\frac{\Delta t_{m}-\Delta t}{\Delta t_{m}-\Delta t_{f}}
$$

em que:

$\phi_{\mathbf{t}_{-} \mathrm{PDT}}=$ porosidade derivada do perfil DT;

$\Delta \mathbf{t}_{\text {ma }}=$ tempo de trânsito da matriz (para arenito, dado por $55 \mu s / f t)$;
$\Delta \mathbf{t}=$ tempo de trânsito lido no perfil;

$\Delta \mathbf{t}_{\mathrm{f}}=$ tempo de trânsito do fluido (valor de referência $189 \mu s / f t)$.

2. Para a obtenção de $\phi_{t \text { PRN }}$ foram efetuados os cálculos usando as seguintes relações:

* Porosidade-densidade $\left(\phi_{\mathbf{D}}\right)$ com correção de fluido (Brock, 1986):

$$
\phi_{D}=\frac{\rho_{m}-\rho}{\rho_{m}-\rho_{f}},
$$

em que:

$\phi_{\mathbf{D}}=$ porosidade derivada do perfil densidade;

$\rho_{\mathrm{ma}}=$ densidade da matriz (para arenito, dado por 2,63 $\left.\mathrm{g} / \mathrm{cm}^{3}\right)$;

$\rho=$ densidade lida no perfil;

$\rho_{\mathrm{f}}=$ densidade do fluido (valor de referência $1,0 \mathrm{~g} / \mathrm{cm}^{3}$ ).

Porosidade a partir da plotagem cruzada RHOB x NPHI, a qual é obtida utilizando-se cartas de correção SCHLUMBERGER (LANDMARK, 2003). A carta apropriada é selecionada baseando-se na densidade do fluido e no tipo de ferramenta neutrônica. Polinomiais são usadas para encontrar uma linha de "equiporosidade" que conecta as três linhas de matriz (arenito, calcáreo e dolomito). As curvas de saída solicitadas, para este conjunto, para obtenção de $\phi_{\mathrm{e}}$, consistem nas porosidades $\phi_{\mathrm{t} \text { PDT }}$ e $\phi_{\mathrm{t} \text { PRN }}$, e a obtida a partir da plotagem cruzada dos dados de RHOB e NPHI.

e) análise volumétrica, que corresponde à escolha dos indicadores de argila e determinação de $\mathrm{V}_{\text {sh }}$, no intervalo de perfil estudado, sendo $\mathrm{V}_{\mathrm{sh}}$ empregado nos cálculos de $\phi_{\text {e PDT }}$ e $\phi_{\text {e PRN }}$. A curva de saída de $\mathrm{V}_{\text {sh }}$ computa os mínimos valores a partir das equações dos indicadores de folhelho selecionados. Alguns indicadores de argila têm como único parâmetro de entrada o perfil GR (como no PDT), neste caso, a curva de entrada utilizada corresponde à curva GR corrigida na etapa de correção ambiental. Para esta etapa, foram escolhidas as equações comumente empregadas para o cálculo de indicadores de folhelho, para os dois conjuntos de perfis, a saber:

* GR Linear, na qual essa se compara o volume de argila/folhelho ao índice de Raios Gama $\left(\mathrm{I}_{\mathrm{GR}}\right)$, sendo a mais comumente usada dada por (Crain, 1986):

$$
I_{G R}=V_{\text {shLinea } r}=\frac{G R_{\log }-G R_{\min }}{G R_{\max }-G R_{\min }}
$$

em que:

$\mathrm{V}_{\text {sh_Linear }}=$ volume de argila calculado a partir GR Linear;

$\mathrm{GR}_{\log =}$ valor de GR da formação lido no perfil;

$\mathrm{GR}_{\min }=$ valor mínimo de GR (areia limpa);

$\mathrm{GR}_{\max }=$ valor máximo de GR (folhelho). 
Larionov, utilizado para rochas antigas (Crain, 1986):

$$
V_{\text {sh LariOld }}=0,3 \quad\left\lfloor 2^{\left(2 . V_{s_{h}} \text { Linear }\right)}-1,0\right\rfloor,
$$

em que:

$\mathrm{V}_{\text {shLariold }}=$ volume de argila obtido a partir da equação de Larionov, expresso como fração da rocha;

$\mathrm{V}_{\text {shLinear }}=$ volume de argila obtido do GR Linear, expresso como fração da rocha.

Para o cálculo do volume de argila, Larionov apresenta duas equações baseadas na idade da rocha: uma para rochas do Terciário (rochas jovens), e outra para rochas mais antigas. Os arenitos estudados nesse caso (Arenito Namorado) correspondem ao período Cretáceo, ou seja, pela classificação de Larionov, são rochas "antigas", por isso a escolha dessa equação.

* Power Law, que é uma equação não-linear que calcula um valor de $\mathrm{V}_{\mathrm{sh}}$ menor ou igual ao da fórmula linear (Figura 5).

* Método Slope, no qual se calcula $\mathrm{V}_{\mathrm{sh}}$ utilizando-se os perfis NPHI e RHOB (Figura 6), com a plotagem cruzada de $\phi_{\mathrm{N}}$ e $\phi_{\mathrm{D}}$. A partir da verificação de uma linha de areia limpa, as polinomiais são obtidas até o ponto denominado ponto de folhelho, em que a linha correspondente determina o volume de argila.

\section{f) cálculo de $\phi_{\mathrm{e}}$ a partir de PRN e PDT}

1. $\phi_{\mathrm{e} \text { PRN }}$ foi calculada a partir da seguinte equação empírica a seguir (LANDMARK, 2003):

$$
\phi_{e_{-} P R N}=\frac{\left(14,5 \cdot \phi_{N_{\text {corr }}}\right)+\left(50,5 \cdot \phi_{D_{\text {corr }}}\right)}{65}
$$

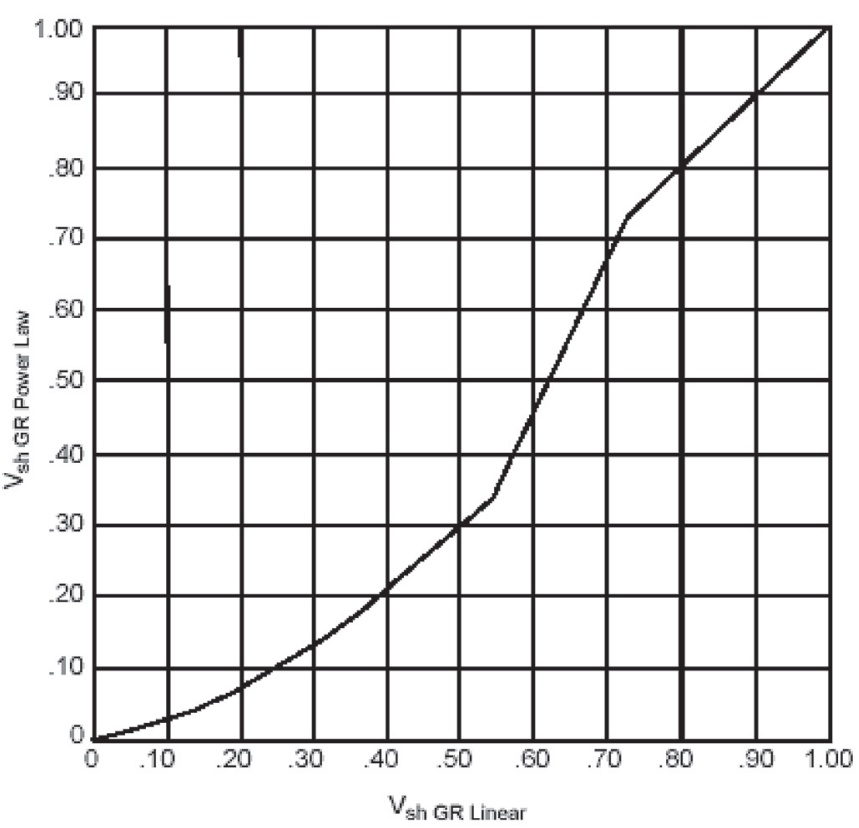

Figura 5. Relação Power Law x GR Linear para o cálculo de $V_{s h}(L A N D M A R K, 2003)$.

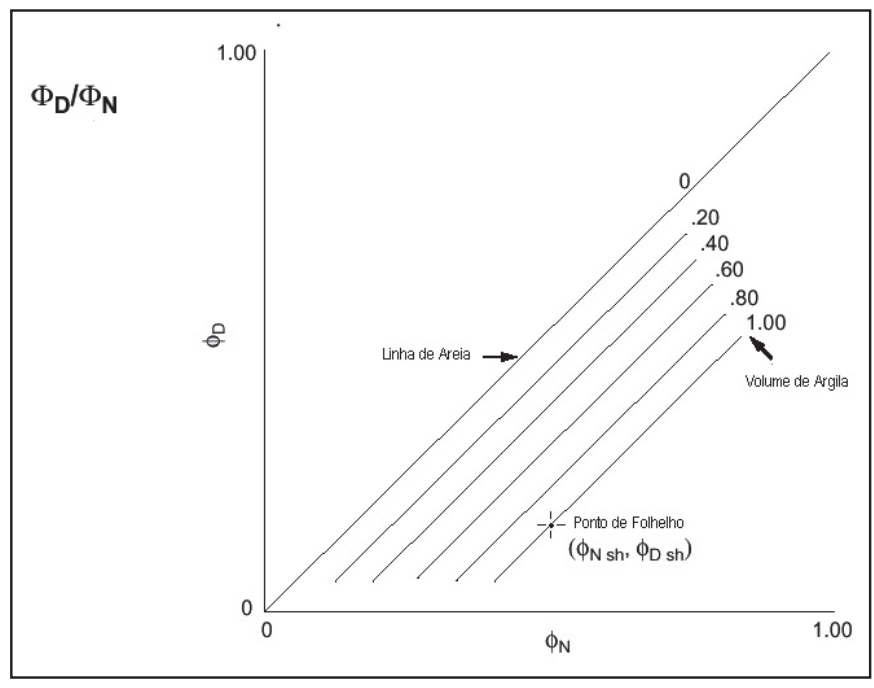

Figura 6. $V_{s h}$ a partir da plotagem cruzada $\Phi_{N} x \Phi_{D}$ (modificado de LANDMARK, 2003).

em que:

$\phi_{\mathrm{e} \text { PRN }}=$ porosidade efetiva obtida a partir da porosidade neutrônica e da porosidade densidade;

$\phi_{\mathrm{N}}=$ porosidade neutrônica corrigida;

$\phi_{\mathbf{D}}=$ porosidade densidade corrigida.

As correções das $\phi_{\mathrm{e}}$ a partir do valor extraído do perfil RHOB e NPHI, já eliminando o efeito da argila, são demonstradas a seguir:

$$
\begin{aligned}
& \phi_{D_{c o r r}}=\phi_{D}-\left(V_{k l} \phi_{D k l}\right) \\
& \phi_{N_{c o r r}}=\phi_{N}-\left(V_{k l} \phi_{N_{k l}}\right)
\end{aligned}
$$

em que:

$\phi_{\text {D corr }=}$ porosidade corrigida a partir da porosidade densidade;

$\phi_{\mathrm{D}}=$ porosidade aparente obtida do perfil de densidade pela Equação (2);

$\mathrm{V}_{\mathrm{sh}}=$ volume de argila fornecido pelo PETROWORKS - PRO;

$\phi_{\mathrm{Dsh}}=$ valor da porosidade densidade relativa ao folhelho;

$\phi_{\mathrm{N} \text { corr }}=$ porosidade neutrônica corrigida obtida a partir da porosidade neutrônica;

$\phi_{\mathrm{N}}=$ porosidade aparente obtida do perfil de porosidade neutrônica;

$\phi_{\mathrm{Nsh}}=$ valor da porosidade neutrônica relativa ao folhelho.

2. Para cálculo de $\phi_{\mathrm{e} \text { PDT }}$ foi utilizada a equação empírica a seguir (LANDMARK, 2003): 


$$
\phi_{e_{-} P D T}=K\left[\left(1-\frac{\Delta t_{m}}{\Delta t}\right)-V_{h}\left(1-\frac{\Delta t_{m}}{\Delta t_{h}}\right)\right],
$$

em que: $\phi_{\mathrm{t} \text { PDT }}=$ porosidade efetiva obtida a partir dos dados do
perfil acústico (DT);

$\Delta \mathrm{t}_{\mathrm{ma}}=$ tempo de trânsito da onda acústica da matriz nesse caso, arenito;

$\Delta \mathrm{t}=$ tempo de trânsito da onda acústica lido do perfil DT;

$\mathbf{V}_{\mathrm{sh}}=$ volume de argila calculado na análise volumétrica;

$\Delta \mathrm{t}_{\mathrm{sh}}=$ tempo de trânsito da onda acústica do folhelho;

$\mathrm{K}=$ fator empírico Raymer-Hunt-Gardner (valor de referência 0,6250 ).

Finalmente, a diferença percentual é calculada pela fórmula:

$$
\operatorname{Diferença~Percentual~}(\%)=\frac{\left(\phi_{e_{-} P R N}-\phi_{e_{-} P D T}\right) \times 100}{\phi_{e_{-} P R N}} \text {, }
$$

em que:

$\phi_{\text {e_PRN }}=$ porosidade efetiva obtida a partir de PRN;

$\phi_{\mathrm{e}_{\_} \text {PDT }}=$ porosidade efetiva obtida a partir de PDT.

METODOLOGIA Para a realização deste trabalho, foram empregados dados de perfis de poços do Campo de Namorado, Bacia de Campos, litoral norte do Estado do Rio de Janeiro, e da Bacia de Almada, sul do Estado da Bahia. Uma breve descrição do processamento desses dados se faz necessário nesta seção.

Poços do Campo de Namorado Ocupam a região central do reservatório e foram analisados através do conjunto básico de perfis composto por DT, ILD, GR, RHOB e NPHI. Os dados desses poços foram fornecidos pela Agência Nacional de Petróleo (ANP), e correspondem a um banco de dados de 56 poços verticais e direcionais. Os dados são compostos pelos perfis GR, presente em 55 poços; ILD, presente em todos os poços; DT, presente em 18 poços; RHOB, presente em todos os poços, e NPHI, presente em 54 poços. A ausência desse conjunto completo de perfis na maioria dos poços verticais conduziu à escolha de cinco poços com o conjunto básico completo, os quais são: 3-NA-0001A, 3-NA-0002, 3-NA-0004, 7-NA-0007 e 7-NA-0011-A.

A determinação do intervalo de profundidade dos poços, que corresponde ao reservatório, foi baseada na análise de testemunhos determinada pela PETROBRAS e cedida pela ANP para o Campo de Namorado, sendo confirmada pelas curvas interpretativas de volume de argila $\left(\mathrm{V}_{\text {sh }}\right)$ na coluna 1 , densidade e porosidade neutrônica (NPHI x RHOB) na coluna 2, eletrofácies (EFAC) na coluna 3, porosidade efetiva e saturação de água $\left(\phi_{\mathrm{e}} \times \mathrm{S}_{\mathrm{w}}\right)$ na coluna 4, permeabilidade $(\mathrm{K})$ na coluna 5 , e, resistividade corrigida para os efeitos de poço (ILD) na coluna 6. Todas essas curvas foram geradas pelo PETROWORKS - PRO e, na Figura 7 apresenta-se um exemplo delas para o caso específico do poço 3- NA0001-A, com destaque para o intervalo entre 2987 e $3015 \mathrm{~m}$. Por outro lado, a curva de EFAC corresponde a uma curva de fácies classificada como: 1 = reservatório, $2=$ cimento e $3=$ folhelho, e, encontra-se num intervalo variando de 0 a 4 .

Para a verificação da confiabilidade do uso do PDT na obtenção de $\phi_{\mathrm{t}}$ e $\phi_{\mathrm{e}}$ para o reservatório $\left(\phi_{\mathrm{t} \text { PDT }}\right.$ e $\left.\phi_{\mathrm{e} \text { PDT }}\right)$, foi realizada uma comparação destes valores com os obtidos pelo PRN $\left(\phi_{t}\right.$ PRN e $\left.\phi_{\text {e PRN }}\right)$ e de ambos com valores determinados em laboratório. Foram realizados três tipos de comparação dos dados do Campo de Namorado, descritos na seqüência a seguir:

a) para obter e comparar as curvas entre si, os valores de $\phi_{\text {e PDT }}$ e $\phi_{\text {e PRN }}$, obtidos pela análise petrofísica dos perfis, foram representados graficamente em função da profundidade. Para mensurar a diferença entre os valores de $\phi_{\mathrm{e}}$ em cada ponto de cada curva, foram calculados: a diferença absoluta entre esses valores, representando-a graficamente em função da profundidade, a freqüência da distribuição dos valores de $\phi_{\mathrm{e}}$, a diferença percentual relativa para cada poço do Campo de Namorado, e o cálculo do erro médio quadrático (rms) correspondente;

b) para a validação dos métodos usados, foi feito um gráfico comparando os valores pontuais de $\phi_{t}$, determinados pela PETROBRAS em laboratório, usando amostras de testemunhos dos poços do Campo de Namorado (fornecidos pela ANP junto com os dados de poço), com os valores de $\phi_{\mathrm{t} \text { PDT }}$ e $\phi_{\mathrm{t} \text { PRN }}$, para as mesmas profundidades de poço. Pelo fato de algumas análises de laboratório terem sido realizadas em amostras localizadas fora dos limites de profundidade do reservatório, aqui determinados, alguns poços tiveram poucos dados experimentais para comparação, respeitando-se, todavia, a existência de no mínimo três pontos. Os dados foram expressos em forma gráfica comparativa em função da profundidade em que foram obtidos.

Poços da Bacia de Almada Foram analisados os poços 1BAS-36 e 1-SSA-1-BA da Bacia de Almada, através do conjunto reduzido de perfis, composto pelas curvas de GR, DT e ILD para os poços. Esses dados dos poços, cedidos também pelo ANP, fazem parte de um banco de dados das bacias de Camamu - Almada. $\mathrm{Na}$ determinação dos valores de $\phi_{\mathrm{e}}$ para a Formação Urucutuca, foi realizada, primeiramente, a transformação de dados analógicos, das figuras originais, para dados digitais, nas coordenadas numéricas dos perfis. Na seqüência, foram realizadas as etapas de obtenção de $\phi_{\text {e PDT, }}$, para o intervalo do perfil correspondente à essa formação para cada poço, baseados em informações da literatura. Segundo Netto \& Sanches (1991) e Netto et al. (1994), a profundidade da formação corresponde aos intervalos 400 a 700 $\mathrm{m}$ para o poço 1-BAS-36 e de 70 a $650 \mathrm{~m}$ para o poço 1-SSA-1BA. Para auxiliar na análise, foram construídos histogramas para cada poço, de valores de $\phi_{\mathrm{e}}$ em função de blocos de valores, na seqüência de 0 a 0,5 com intervalo de 0,05 .

RESULTADOS A geração dos valores de $\phi_{\mathrm{e} \text { PRN }}$ e $\phi_{\mathrm{e} \text { PDT }}$ em função da profundidade, com a utilização do aplicativo PETROWORKS - PRO, foi realizada nos poços 3-NA-0001-A, 3-NA0002, 3 -NA-0004, 7-NA-0007 e 7- NA-0011-A do Campo de Namorado na Bacia de Campos - RJ. Por brevidade, somente para o poço 3 NA 0001A os resultados são apresentados nas Figuras 8 e 9 . Os valores variam entre 0,05 e 0,30 , considerando os dois projetos. Na Figura 10, apresenta-se a comparação dos valores de $\phi_{\mathrm{e} \text { PRN }}$ e $\phi_{\mathrm{e} \text { PDT }}$ no intervalo do reservatório para o poço 3 -NA-0001-A. Pode-se observar que ambas as curvas apresentam comportamento semelhante, entretanto, $\phi_{\mathrm{e} \text { PRN }}$ apresenta valores, em geral, maiores que $\phi_{\mathrm{e} \text { PDT }}$. Como descrito nas equações anteriormente apresentadas, os parâmetros que influenciam na obtenção de $\phi_{\mathrm{e} \text { PDT }}$ são $\phi_{\mathrm{t}} \mathrm{e} \mathrm{V}_{\mathrm{sh}}$. A Figura 11, entretanto, mostra 


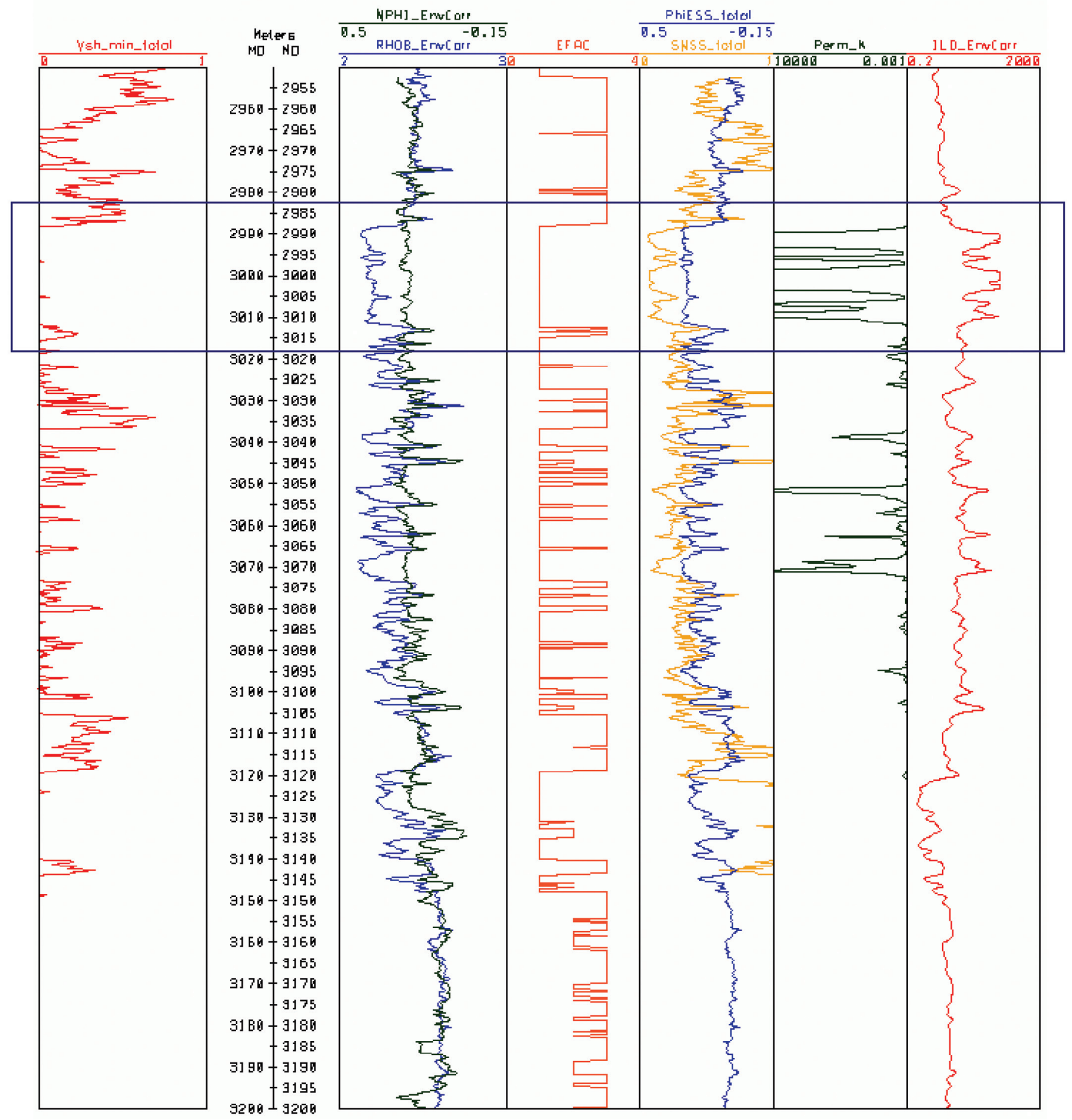

Figura 7. Conjunto de curvas geradas pelo PETROWORKS - PRO para o poço 3-NA-0001-A do Campo de Namorado, com destaque o intervalo analisado correspondente ao reservatório.

a comparação entre as curvas de $\phi_{\mathrm{t} \_\mathrm{PDT}}$ e $\phi_{\mathrm{t} \text { PRN }}$ para o mesmo conjunto de dados. Observa-se um mesmo comportamento nas curvas, com valores de $\phi_{\mathrm{t}}$ pDT ligeiramente maiores que os de $\phi_{\mathrm{t} \text { PRN }}$. A diferença encontrāa é insignificante, o que demonstra ser pequena a contribuição de $\phi_{t}$ nos valores diferenciados de $\phi_{t}$ ${ }_{\text {PDT }}$ e $\phi_{\mathrm{t} \text { PRN }}$. Na Figura 12, mostra-se a diferença entre as curvas de $V_{\text {sh }}$ obtidas para PDT e PRN, observando-se que o volume de argila $\mathrm{V}_{\text {sh PDT }}$ é, geralmente, maior do que $\mathrm{V}_{\text {sh PRN }}$, e que o comportamento de $\mathrm{V}_{\text {sh }}$ PDT é proporcional ao comportamento da curva de $\phi_{\mathrm{e} \text { PDT }}$ na Figura 10. Dessa forma, a diferença de $\phi_{\mathrm{e}}$, observada neste poço, pode ser explicada pelo $\mathrm{V}_{\text {sh }}$, visto que a contribuição deste parâmetro na obtenção de $\phi_{\mathrm{e}}{ }_{\mathrm{PDT}}$, no intervalo do reservatório, para o poço 3-NA-0001-A, é mais significativa do que a contribuição de $\phi_{\mathrm{t}}$. Em virtude dos valores de $\mathrm{V}_{\text {sh PDT }}$ serem superestimados em relação à $\mathrm{V}_{\text {sh } \mathrm{PRN}}$, a correção do $\mathrm{V}_{\text {sh }}$ para o cálculo de $\phi_{\mathrm{e} \text { PDT }}$ é maior do que para $\phi_{\mathrm{e} \text { PRN }}$, acarretando, então, valores menores para de $\phi_{\mathrm{e}}$ PDT. A Figura 13 mostra a diferença pontual entre os valores de $\phi_{\mathrm{e} \text { PRN }}$ e $\phi_{\mathrm{e}}$ PDT. Observa-se, nesta figura, que os valores de $\phi_{\mathrm{e} \text { PRN }}$ são, em geral, maiores que $\phi_{\mathrm{e} \text { PDT }}$, com diferença da ordem de 0,05 . Uma comparação dos valores de $\phi_{\mathrm{e} \text { PRN }}$ e $\phi_{\mathrm{e} \text { PDT }}$ através da análise da distribuição de freqüência para o poço 3-NA-0001-A, no intervalo do reservatório, é apresentada na Figura 14, onde pode-se observar a equivalência das distribuições. A diferença percentual entre os 


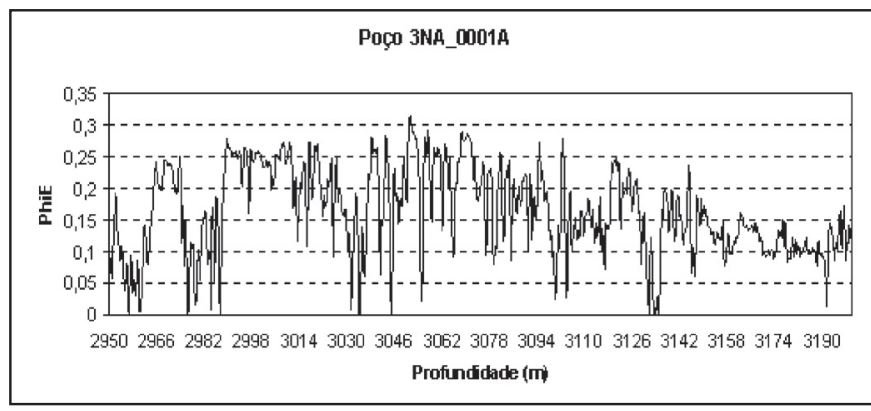

Figura 8. Curva de $\phi_{e}$ do poço 3-NA-0001-A do Campo de Namorado $(P R N)$.

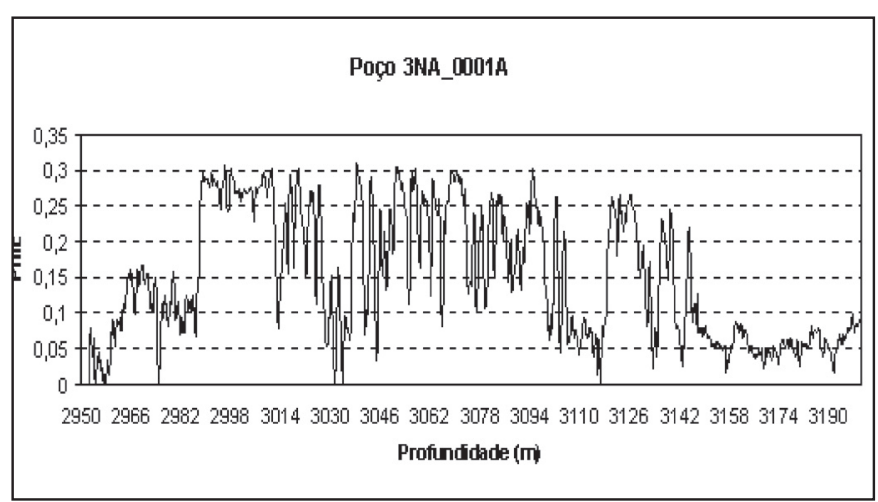

Figura 9. Curva de $\phi_{e}$ do poço 3-NA-0001-A do Campo de Namorado (PDT).

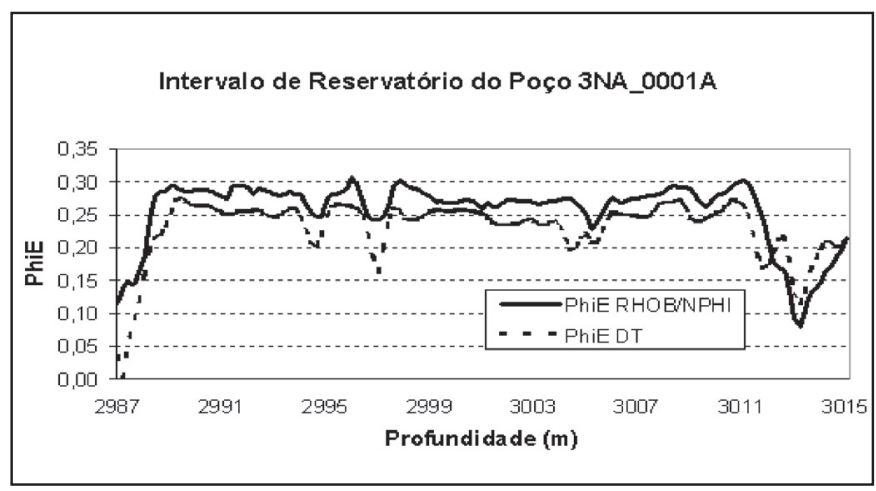

Figura 10. Comparação das curvas de $\phi_{e}$ do intervalo de reservatório do poço 3-NA-0001-A do Campo de Namorado.

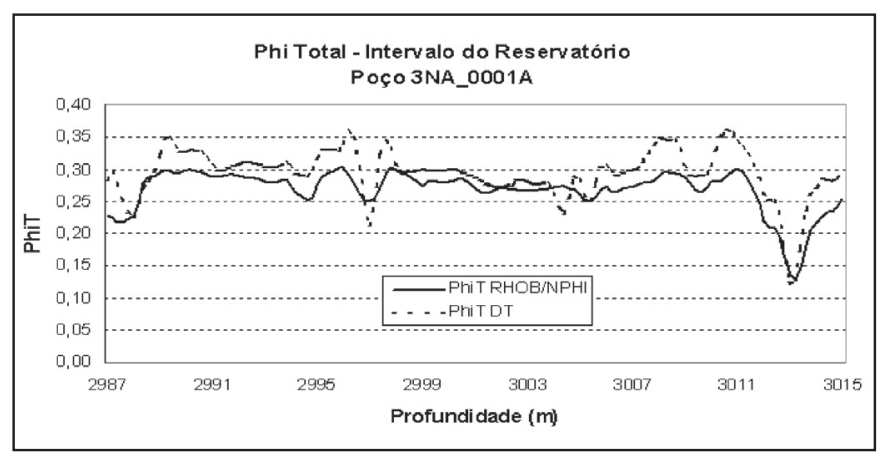

Figura 11. Comparação das curvas de $\phi_{t}$ do intervalo de reservatório do poço 3-NA-0001-A do Campo de Namorado.

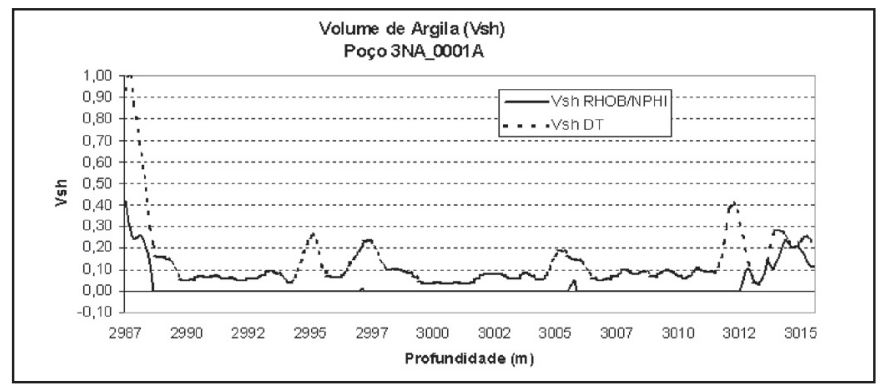

Figura 12. Comparação das curvas de $V_{\text {sh }}$ para PRN e PDT, para o poço 3-NA-0001-A do Campo de Namorado.

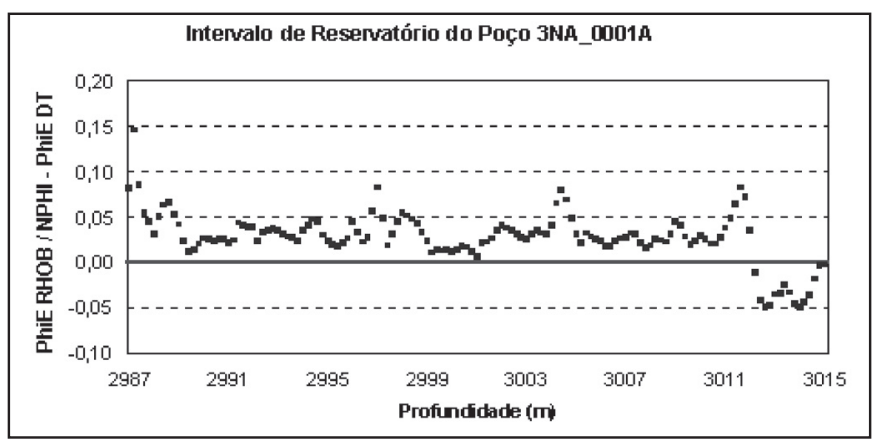

Figura 13. Diferença percentual entre os valores de $\phi_{e}$ no intervalo do reservatório para o poço 3-NA-0001-A.

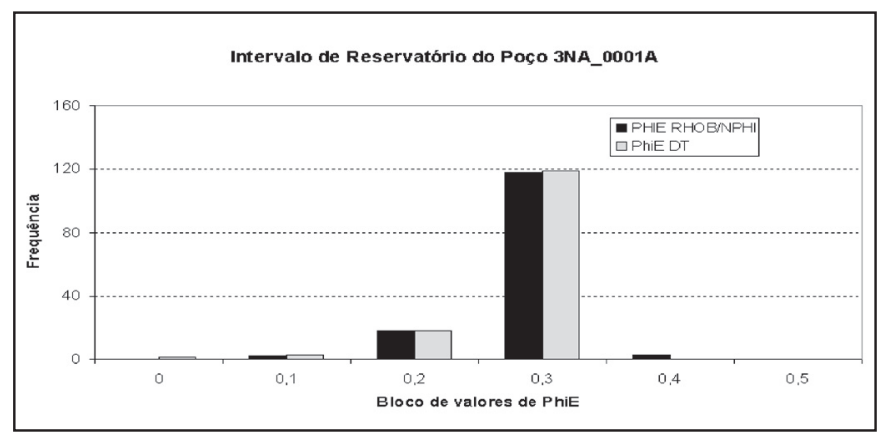

Figura 14. Comparação da distribuição de $\phi_{e P D T}$ e $\phi_{e P R N}$ no intervalo do reservatório do poço 3-NA-0001-A do Campo de Namorado.

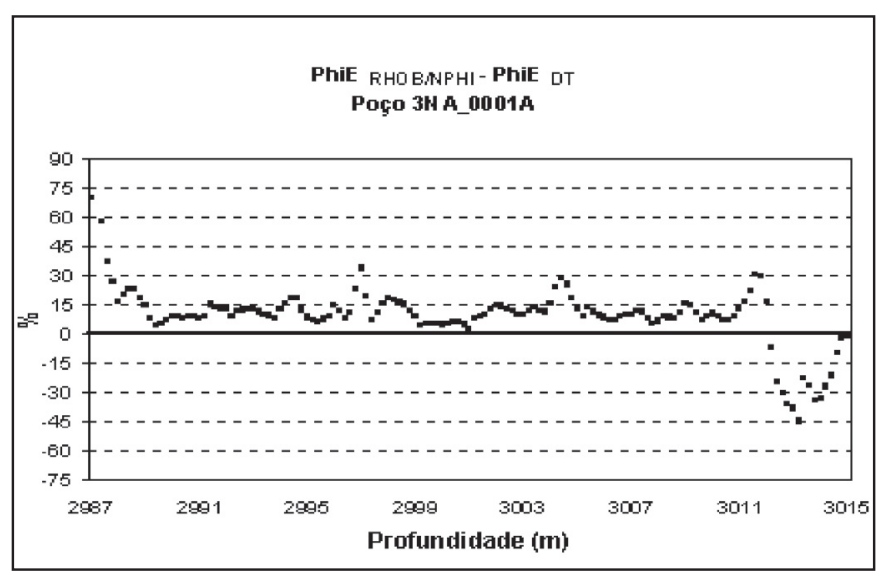

Figura 15. Diferença percentual entre os valores de $\phi_{e}$ no intervalo do reservatório para o poço 3-NA-0001-A do Campo de Namorado. 


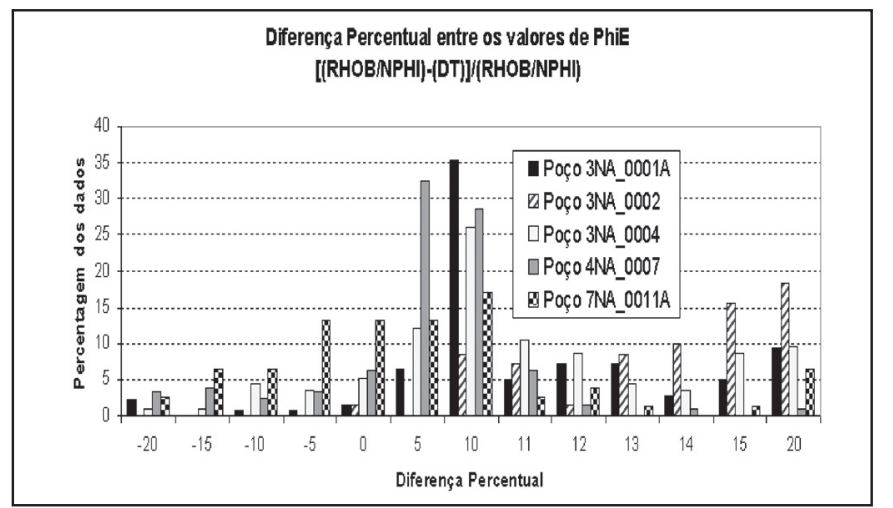

Figura 16. Diferença percentual entre os valores de $\phi_{e P D T} e$ $\phi_{e \text { PRN }}$ para os cinco poços estudados no Campo de Namorado.

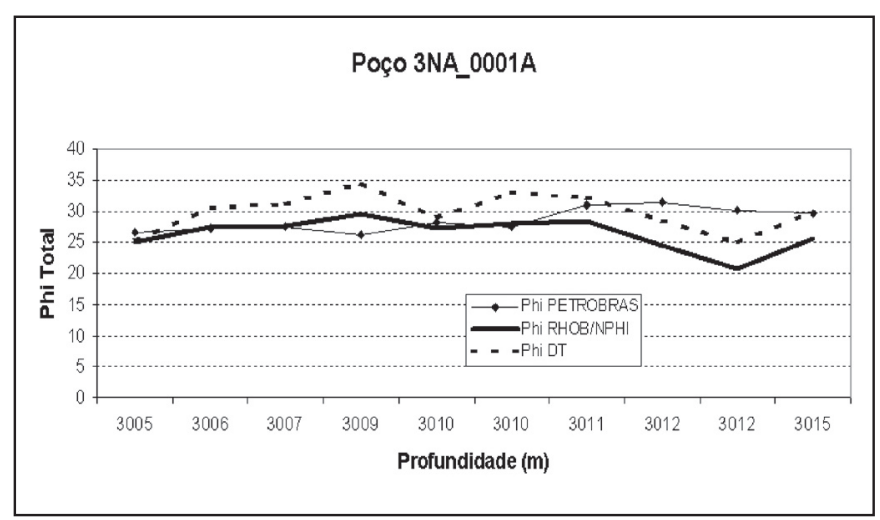

Figura 17. Comparação entre os valores pontuais de $\phi_{\text {t }}$ obtidos da PETROBRAS, PRN e PDT, para o Poço 3-NA-0001-A do Campo de Namorado.

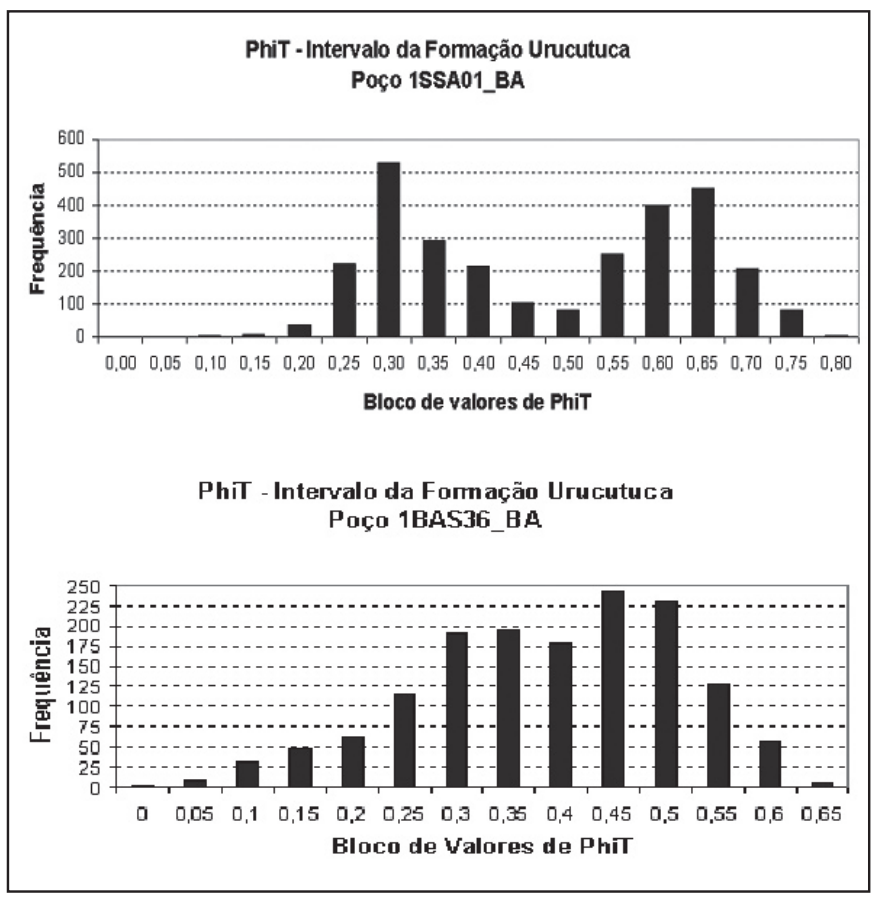

Figura 18. Curva de distribuição dos valores de $\phi_{t}$ no intervalo da Formação Urucutuca para os poços 1-SS-01-BA e 1-BAS36- $B A$.

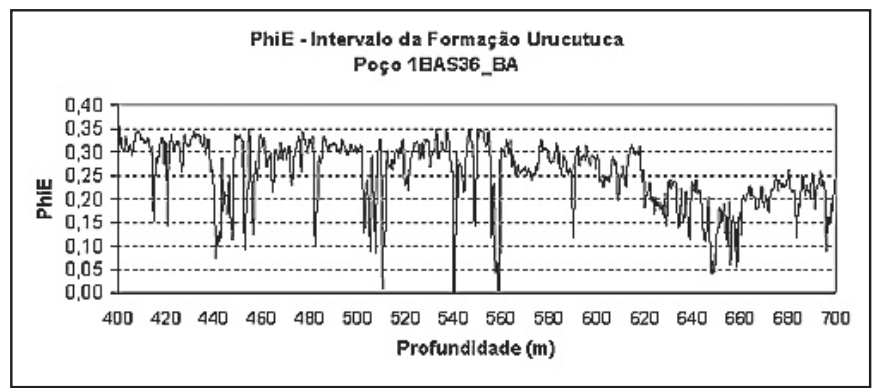

Figura 19. Curva de $\phi_{e}$ no intervalo da Formação Urucutuca para o poço 1-BAS-36- $B A$.

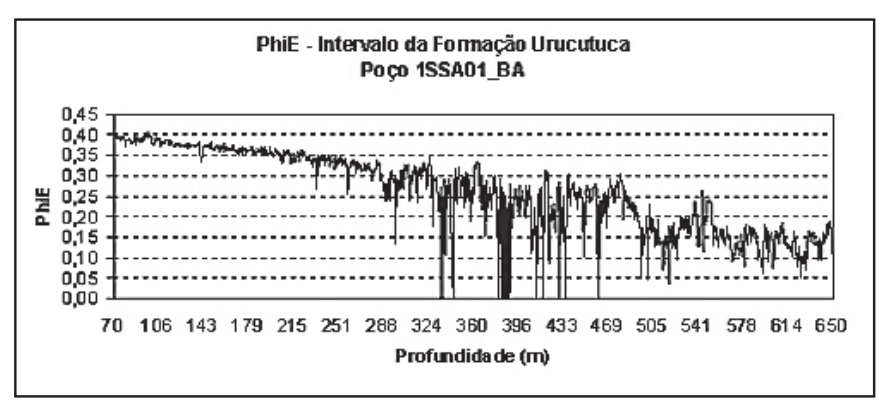

Figura 20. Curva de $\phi_{e}$ no intervalo da Formação Urucutuca para o poço 1-SSA-01-BA.

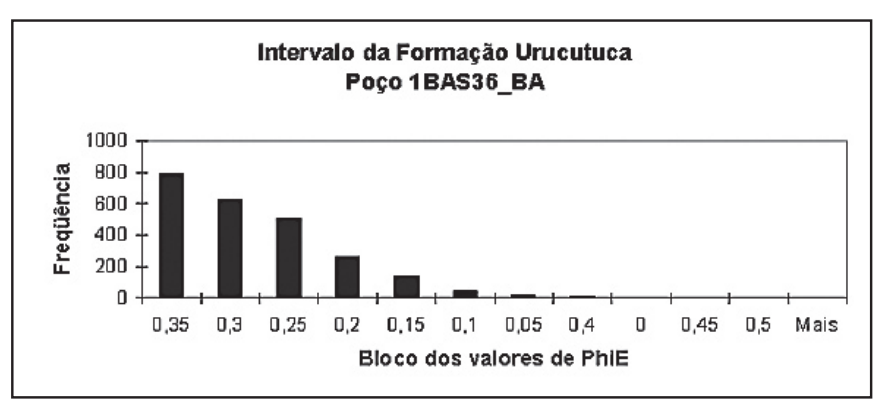

Figura 21. Distribuição de $\phi_{e}$ para o poço 1-BAS-36-BA.

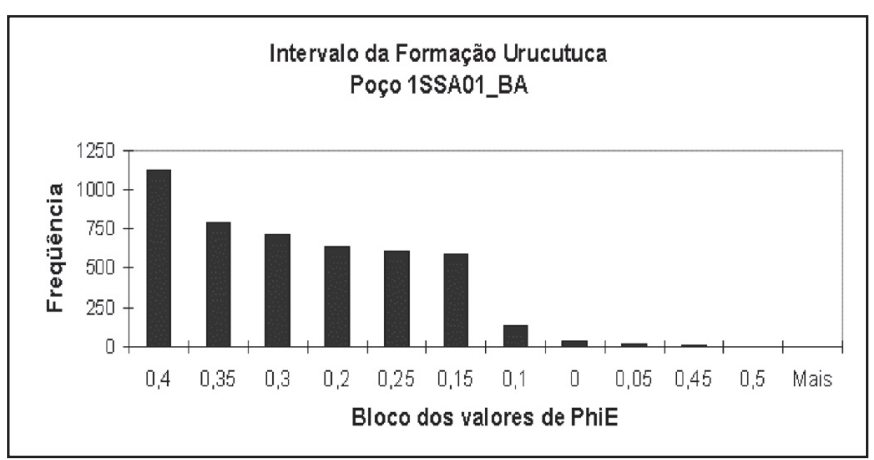

Figura 22. Distribuição de $\phi_{e}$ para o poço 1SSA01-BA. 
valores de $\phi_{\text {e PRN }}$ e $\phi_{\text {e PDT }}$ foi calculada pela Equação (10), sendo apresentada na Figura 15. De acordo com os dados percentuais, a diferença dos valores entre $\phi_{\mathrm{e} \text { PRN }}$ e $\phi_{\mathrm{e}}$ PDT é menor ou igual que $+15 \%$ em cerca de $72 \%$ dos pontos calculados. Por outro lado, os valores obtidos para as porosidades através de PRN e PDT para os 5 poços vêm mostrados na Figura 16. Chama-se atenção para o poço 3-NA-0002 onde esta equivalência é menor do que para os demais poços. $\mathrm{O}$ erro médio quadrado entre os valores de PDT e os valores de PRN foi de $13,16 \%$ para o poço 3-NA-0001-A.

Para verificar a confiabilidade dos valores obtidos nos cálculos apresentados usando PRN e PDT, foi realizada a comparação dos valores de $\phi_{\mathrm{t}}$, obtidos por esses métodos com valores experimentais determinados pela PETROBRAS e cedidos pela ANP, fazendo análise de laboratório para o Campo de Namorado, em profundidades equivalentes. Observa-se, de maneira geral, na Figura 17, que os valores pontuais de $\phi_{\mathrm{t} \text { PDT }}$ estão em conformidade com os valores encontrados tanto pela PETROBRAS, quanto também $\phi_{\mathrm{t} \text { PRN }}$. Correspondem a valores da ordem de 0,20 a 0,30 para $\phi_{\mathrm{t}}^{-}$PDT , contra valores experimentais da ordem de 0,24 a 0,34, e de 0,20 a 0,34 para $\phi_{\mathrm{tPRN}}$. Estes resultados confirmam a confiabilidade dos valores obtidos pelo uso de PDT.

Confirmada a confiabilidade dos resultados obtidos via PDT, apresentou-se como viável a análise da porosidade dos dois poços da Bacia de Almada. Os valores de $\phi_{t}$ obtidos para o intervalo da Formação Urucutuca, para os poços 1-BAS-36 e 1-SSA-1-BA estão representados, em função de sua freqüência de distribuição, na Figura 18. Por outro lado, os valores calculados para $\phi_{\mathrm{e}}$, em função da profundidade, no intervalo da Formação Urucutuca, para os poços estudados na Bacia de Almada, estão representados nas Figuras 19 e 20. Os valores de $\phi_{\mathrm{e}}$ observados podem ser justificados pela pouca profundidade da formação, o que implica em menor fator de compactação e numa alta porosidade. Pode-se observar que a porosidade calculada em função do perfil DT (Figura 20) reflete bem o efeito da compactação no poço 1- SSA-1-BA, visto que, com o aumento da profundidade, ocorre o decréscimo de $\phi_{\mathrm{e}}$. Para esses poços, os valores de $\phi$ foram representados em função da freqüência de distribuição (Figuras 21 e 22). Observa-se nessas figuras que o valor médio $\phi$, para esse intervalo, no poço 1-BAS36 , está compreendida entre 0,30 e 0,35 , que compreende cerca de $57 \%$ dos pontos. No caso do poço 1-SSA-1-BA, esses valores estão distribuídos de maneira quase uniforme entre 0,15 e 0,35, compreendendo cerca de $70 \%$ dos pontos. Entretanto, o maior valor corresponde a 0,40 , compreendendo $24 \%$ dos pontos.
CONCLUSÕES Neste trabalho foram empregados dados de perfis de poço da Bacia de Campos /RJ (Campo de Namorado) e da Bacia de Almada/BA para o cálculo das porosidades efetiva ou total das suas formações geológicas. Esta estimativa normalmente emprega um conjunto composto de cinco perfis (DT, GR, ILD, NPHI e RHOB), que designamos como Projeto RHOB/NPHI ou PRN. Entretanto, os dados referentes à Bacia de Almada apresentam-se com apenas três perfis (DT, GR, ILD), que designamos como Projeto DT ou PDT. Mesmo com a falta dos perfis RHOB e NPHI em Almada, decidiu-se estimar as porosidades, testando a confiabilidade deste método com os dados completos do Campo de Namorado, e verificando os resultados com medidas experimentais de laboratório. Para realizar essa verificação, foram comparados os valores de $\phi_{\mathrm{e} \text { PDT }}$ com $\phi_{\mathrm{e} \text { PRN }}$. Assim, $\phi_{\mathrm{e} \text { PDT }}$ para os reservatórios dos poços do Campo de Namorado apresentou-se com valores da ordem de 0,20 a 0,30 , enquanto que, $\phi_{\mathrm{e} \text { PRN }}$ apresentou valores entre 0,30 a 0,35 . Portanto, a diferença entre os valores de $\phi_{\mathrm{e}}$ PDT são, em média, menores dos que os de $\phi_{\text {e PRN }}$ na ordem de 0,05 a 0,10 em valor absoluto. A variação entre os valores obtidos por ambos foi da ordem de $15 \%$ em $73 \%$ dos dados analisados. Assim sendo, uma vez verificada a confiabilidade dessa metodologia, a mesma foi empregada no cálculo da $\phi_{\mathrm{e}}$ de dois poços da Bacia de Almada, resultando em valores de $\phi$, da ordem de 0,65 a 0,80 , devido à baixa profundidade e menor fator de compactação da Formação Urucutuca. A $\phi_{\mathrm{e}}$ calculada foi da ordem de 0,30 a 0,35 para o poço 1-BAS-36; para o poço 1-SSA-1-BA, mostrou-se distribuída entre 0,15 e 0,30 , para $70 \%$ dos pontos, e da ordem de 0,40 para $24 \%$ dos pontos. A metodologia proposta mostrouse, assim, consistente, podendo ser utilizada em outros casos de exploração em diferentes bacias sedimentares, onde somente se pode estimar a porosidade (efetiva ou total) a partir de um número limitado de perfis.

Agradecimentos Os autores agradecem à ANP pela liberação dos dados das Bacias de Almada e Campos, à LANDMARK pela cessão do pacote de programas interpretativos utilizado neste trabalho e aos geólogos da PETROBRAS/UNBC pelo estágio no uso desses programas. Também, agradecem ao LENEP pelo uso de suas instalações e ao Prof. C. A. Dias pelas numerosas sugestões, que contribuíram para melhorar o presente texto. Finalmente, agradecem à ANP pela bolsa de mestrado da aluna Shirley Rabelo, e ao CNPq pela bolsa de produtividade em pesquisa de Abel Carrasquilla.

\section{Referências}

Asmus H.E. \& Ponte F.C. 1973. The brazilian marginal basins: In: H.E. Nairn \& F.G Stehli (eds). The ocean basins and margins. Vol. 1, The South Atlantic, New York, Plenum Press, p. 87-132.

Brock J.G. 1986. Applied open-hole log analysis. Vol. 2. Texas, Gulf Publishing Company, 284p.

Bruhn C.H.L. \& Moraes M.A.S. 1989. Turbiditos da Formação Urucutuca na Bacia de Almada, Bahia: um laboratório de campo para estudo de reservatórios canalizados. Boletim de Geociências da PETROBRÁS, 3(3): 235-267.

Crain E.R. 1986. The Log Analysis Handbook. Vol. 1. Quantitative Log Analysis Methods. Oklahoma, Penn Well Books, 684p.

Hallenburg J.K. 1997. Standard methods of geophysical formation evaluation. Lewis Publishers, Boca Raton, Fl, 442 p.

LANDMARK. 2003. Petroworks Manual. OpenBooks, Landmark Graphics Corporation.

Meneses S.X. \& Adams T. 1990. Ocorrência de resistividades anômalas no Campo de Namorado, Bacia de Campos. Boletim de Geociências da PETROBRÁS, 4(2): 183-188.
Milani E. J., Brandão J. A. S. L., Zalan P. V., Gamboa L.A.P. 2000. Petroleum in the Brazilian continental margin: geology, exploration, results and perspectives. Revista Brasileira de Geofisica, 18(3): 352-396.

Netto A.S.T. \& Sanches C.P. 1991. Roteiro Geológico da Bacia de Almada, Bahia. Revista Brasileira de Geociências, 21(2): 186-198.

Netto A.S.T., Wanderley Filho J.F., Feijó F.J. 1994. Bacias de Jacuípe, Camamu e Almada. Boletim de Geociencias da PETROBRAS, 8(1): 173-184.

SCHLUMBERGER. 1998. Searching for oil and gas in the land of giants - Special edition on Brazil. Schlumberger, Argentina.

Wyllie M.R.J., Gregory A.R., Gardner L.W. 1956. Elastic Wave Velocities in Heterogeneous and Porous Media. Geophysics, 21(1): 41-70.

Manuscrito A-1534 Revisão aceita em 14 de junho de 2006 